\title{
Fatigue Behavior of Oriented Ultra-High Molecular Weight Polyethylene Prepared by Gel Drawing
}

\author{
Norihiro KaIYa, Atsushi Takahara, and Tisato KaJiYama* \\ Department of Applied Chemistry, Faculty of Engineering, Kyushu University, \\ Hakozaki, Higashi-ku, Fukuoka 812, Japan
}

(Received April 4, 1990)

\begin{abstract}
High-modulus and high-strength PE specimens were prepared from the dry gel film of ultra-high molecular weight polyethylene (UHMWPE) and their fatigue behavior was investigated in terms of dynamic viscoelastic measurement during the fatigue process. In the case of oriented film with draw ratio less than 60 , the maximum of $E^{\prime}$ and the minimum of $\tan \delta$ on approaching the point of failure were observed under small imposed strain amplitude suggesting that the proceeding of orientation of molecular chains under cyclic fatigue. However, this maximum of $E^{\prime}$ and the minimum of $\tan \delta$ were not observed for PE with draw ratio of 100 . The temperature dependence of fatigue strength of drawn PE suggested the contribution of crystalline relaxation process to fatigue mechanism of oriented PE film.

KEY WORDS Ultra-high Molecular Weight Polyethylene / Gel-Drawing

Method / Nonlinear Viscoelasticity / Fatigue Behavior / Dynamic

Viscoelasticity / Crystalline Relaxation /
\end{abstract}

In recent years, various polymers have been an objects of high-strength and high-stiffness materials. In order to reach the theoretical strength of polymers, it is necessary to utilize the strong covalent bonds of polymer chains. High-modulus and high-strength fibers or films have been prepared from flexible polymers by various methods. ${ }^{1}$

Pennings et $a .^{2}$ and Keller et $a l^{3}$ have developed the technique for longitudinal growth of fibrillar crystals of linear polyethylene. The fibers prepared by this method consisted of shish kebab structure and exhibited high modulus and tenacity.

Smith et al. ${ }^{4,5}$ have developed a continuous process for the production of strong and stiff polyethylene fibers which allows direct production of PE fibers by stretching gel at a considerable rate. Also, Smith and Lemstra ${ }^{6}$ prepared the dry gel films by allowing the solvents to evaporate. The high strength PE fibers were prepared from the gel films. The drawing behavior of these dry gel films was dependent on the initial gel concentration and drawing temperature.

The preparation methods of highly oriented polyethylene and the structural or morphological changes of drawn sample have been investigated extensively. However, little attention has been paid on the long terms strength under dynamic deformation. The fatigue behavior of these high-strength polyethylene is an important subject with respect to their practical application.

In this study, the fatigue behavior of high modulus and high strength polyethylene films prepared by drawing dry gel films of UHMWPE were investigated in terms of dynamic viscoelastic measurements during the fatigue process.

* To whom correspondence should be addressed. 


\section{EXPERIMENTAL}

\section{Sample Preparation}

The ultra-high molecular weight polyethylene (UHMWPE) used in this study is Hizex Million $340 \mathrm{M}$ with $M_{w}=2.7 \times 10^{6}$ (Mitsui Petrochemical Co., Ltd.). A $0.5 \%$ w/w polymer solution in decalin was prepared at $433 \mathrm{~K}$ under nitrogen atmosphere and was stabilized by $0.5 \% \mathrm{w} / \mathrm{w}$ (to polymer) of di- $t$-butyl-p-cresol. After one hour stirring, a UHMWPE solution was poured into an aluminum tray. Upon quenching at room temperature, a polymer gel was obtained. The decalin was allowed to evaporate from this gel at room temperature, resulting in formation of a dried gel film. The dried gel films were cut into strips of $20 \mathrm{~mm}$ long and $5 \mathrm{~mm}$ wide. These specimens were elongated to various draw ratios at $398 \mathrm{~K}$ using Tensilon UTM III-500 (Orientec Co., Ltd.). A cross-head speed of $100 \mathrm{~mm} \mathrm{~min}^{-1}$ was employed.

\section{Characterization of Drawn UHMWPE Film}

The wide angle X-ray diffraction (WAXD), the stress-strain, and the differential scanning calorimetric (DSC) measurements were carried out in order to characterize the drawn UHMWPE film.

WAXD patterns were obtained with $\mathrm{Ni}$ filtered $\mathrm{Cu}-K_{\alpha}$ radiation generated from $\mathrm{RU}$ 200 (Rigaku Co., Ltd.). WAXD photographs were taken for a drawn thin film with the X-ray beam normal to the film surface. The degree of orientation of the c-axis was determined for the drawn samples. The X-ray diffraction intensity were measured by a X-ray diffractometer (Rigaku Co., Ltd.).

The mechanical properties of the drawn films were measured at room temperature with a Tensilon UTM III-500 (Orientec Co., Ltd.). The initial length of specimen was $10 \mathrm{~mm}$ and a cross-head speed was $10 \mathrm{~mm} \mathrm{~min}^{-1}$.

The DSC melting thermograms of the drawn samples were recorded with a differential scanning calorimeter DSC Unix (Rigaku Co.,
Ltd.) at a heating rate of $10 \mathrm{~K} \mathrm{~min}^{-1}$ while samples were unconstrained (free) and constrained (fixed). In the case of the unconstrained method, a specimen was normally packed in an aluminum pan. On the other hand, in the constrained method, in order to prevent shrinkage of the drawn films during heating, samples were prepared by winding a piece of film of $10-30 \mathrm{~cm}$ long tightly around a small copper wire following by fixing with epoxy adhesive agent.

\section{Fatigue Test}

The fatigue test was carried out using a dynamic viscoelastic fatigue tester VFA-20 (Orientec Co., Ltd.), which enabled continuous measurements of dynamic viscoelasticity during the fatigue process up to the failure. ${ }^{7-9}$ Fatigue test for drawn UHMWPE films with various draw ratios was performed under the conditions of the testing frequenccy of $10 \mathrm{~Hz}$ and the ambient temperatures of $298 \mathrm{~K}, 323 \mathrm{~K}$, and $348 \mathrm{~K}$. The magnitude of dynamic strain amplitude, $\varepsilon_{\mathrm{d}}$ was in the range of 0.2 to $1.5 \%$. The minimum and the maximum strains imposed on the specimen were zero and $2 \varepsilon_{\mathrm{d}}$, respectively, so that the average strain applied to the specimen was $\varepsilon_{\mathrm{d}}$.

\section{RESULTS AND DISCUSSION}

\section{Characterization of Drawn UHMWPE Film}

Figure 1 shows the WAXD patterns for the drawn UHMWPE film with various draw ratios. The degree of orientation of $c$-axis, $f_{c}$ is indicated in Table I. It is apparent from the sharpness of the X-ray diffraction spots that fairly complete chain orientation is already achieved at a relatively low draw ratio of 20 . In fact, the magnitude of $f_{\mathrm{c}}$ was beyond 0.99 for the all samples studied here. The fact that the intensity of the (200)-reflection is very weak and that of the (020)-reflection is strong, indicates that high degree of planar orientation: orientation of the $b$-axis in the film plane and, accordingly, the orientation of the a-axis to the 
Fatigue Behavior of High-Strength PE

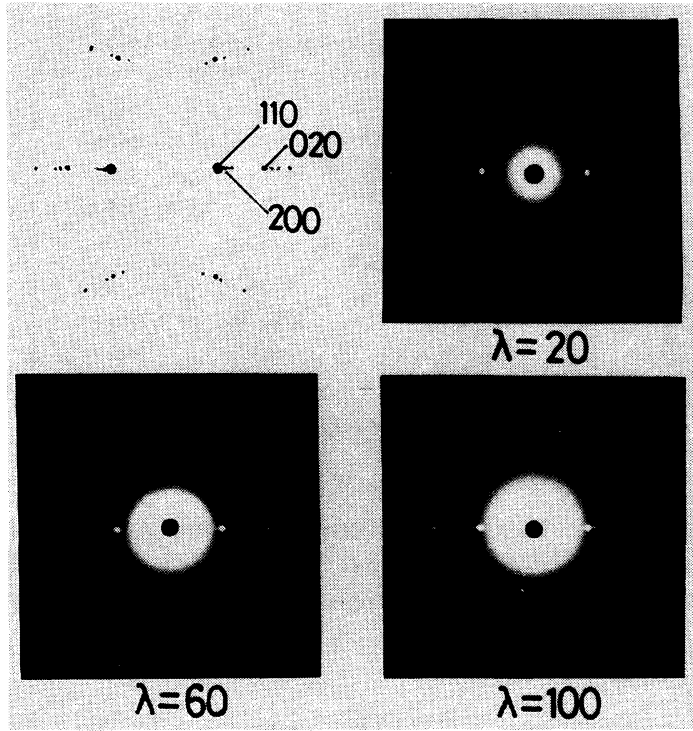

Figure 1. Wide angle $\mathrm{X}$-ray diffraction patterns of the drawn UHMWPE films with draw ratios of 20,60, and 100.

Table I. Degree of orientation, $f_{\mathrm{c}}$, and mechanical properties of drawn UHMWPE as a function of draw ratio

\begin{tabular}{rcccc}
\hline \multicolumn{5}{c}{ Draw ratio } \\
\hline \multicolumn{1}{c}{$f_{\mathrm{c}}$} & $\mathrm{E} / \mathrm{GPa}$ & $\sigma_{\mathrm{b}} / \mathrm{GPa}$ & $\varepsilon_{\mathrm{b}} / \%$ \\
\hline 20 & 0.992 & 40 & 3.0 & 9.3 \\
60 & 0.993 & 78 & 3.3 & 6.4 \\
100 & 0.993 & 127 & 4.3 & 4.4 \\
\hline
\end{tabular}

film thickness.

Figure 2 shows the DSC thermograms of both unconstrained (free) and constrained (fixed) films drawn to various draw ratios. In the case of the unconstrained (free) samples, two melting peaks at the temperature of $419 \mathrm{~K}$ and $426-428 \mathrm{~K}$ were observed. The peak area at higher temperature increased with draw ratio. On the other hand, in the case of constrained (fixed) samples, three endothermic peaks were observed at the temperatures of $417 \mathrm{~K}, 428 \mathrm{~K}$, and $437 \mathrm{~K}$. The peak area at $437 \mathrm{~K}$ increased with draw ratio. Pennings $e t$ $a l .{ }^{11}$ investigated melting behavior of continuous fibrillar polyethylene crystals prepared by

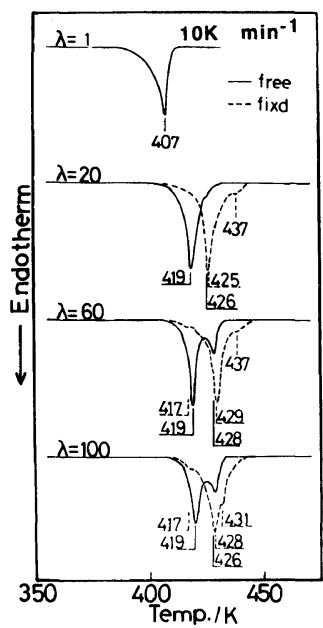

Figure 2. DSC thermograms of the UHMWPE films with draw ratios of 20,60 , and 100 under heating rate of $10 \mathrm{Kmin}^{-1}$. Solid and broken line indicate the DSC thermogram under the unconstrained (free) and the constrained (fixed) conditions, respectively.

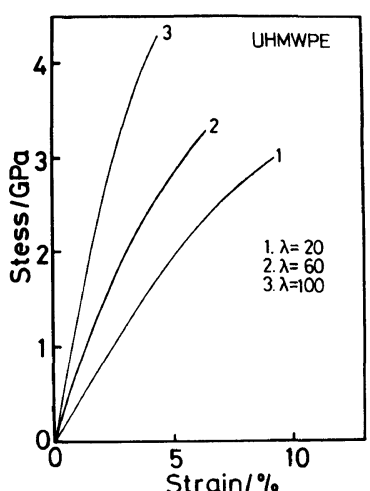

Figure 3. Stress-strain curves for the drawn UHMWPE films with the draw ratios of 20,60 , and 100 . The extension rate was $10 \mathrm{~mm} \mathrm{~min}^{-1}$

surface growth method and revealed that the main peak at $428 \mathrm{~K}$ for constrained fiber was attributed to solid-solid transition of the orthorhombic phase to the hexagonal one and the peak at $437 \mathrm{~K}$ arose from the endotherm associated with trans-gauche conformational change. As the peak area at $437 \mathrm{~K}$ increased with draw ratio, it is apparent that contents of the extended chain crystal increased with draw ratio. 


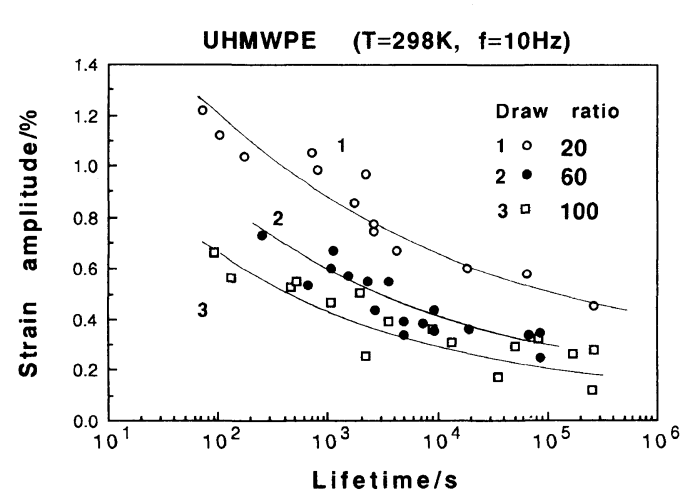

Figure 4. Relationships between dynamic strain amplitude and fatigue lifetime at $298 \mathrm{~K}$ for the drawn UHMWPE films with various draw ratios.

Figure 3 shows the stress-strain curves for the UHMWPE films drawn to various draw ratios. Table I summarizes Young's modulus, $E$, tensile strength, $\sigma_{\mathrm{b}}$ and strain at break, $\varepsilon_{\mathrm{b}}$. The magnitudes of $\mathrm{E}$ and $\sigma_{\mathrm{b}}$ increased with an increase in draw ratio, while $\varepsilon_{\mathrm{b}}$ decreased. Since the orientation function of the $c$-axis of these specimens was not strongly dependent on the draw ratio, these increase in modulus and strength may be ascribed to the increase in number of extended chains. The magnitude of $E$ for the sample with draw ratio of 100 is about a half as large as the theoretical modulus of polyethylene crystal.

\section{Relationships between Fatigue Lifetime and Imposed Strain Amplitude}

Figure 4 shows the relationships between the dynamic strain amplitude and the fatigue lifetime for UHMWPE films with various draw ratios. The fatigue lifetime increases with a decrease in strain amplitude. At the same dynamic strain amplitude level, the fatigue lifetime decreases with an increase in draw ratio.

Figure 5 shows the relationships between the dynamic strain amplitude and the fatigue lifetime for UHMWPE film with draw ratio of 100 at various ambient temperatures. The fatigue strength at $323 \mathrm{~K}$ is lower than those at other ambient temperatures. The ambient

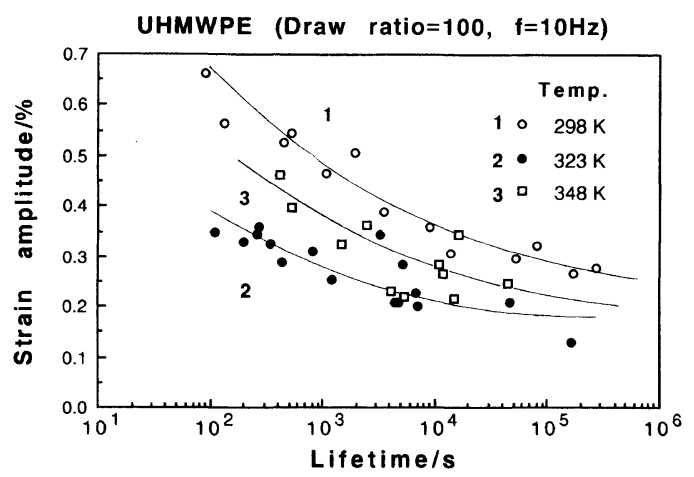

Figure 5. Relationships between dynamic strain amplitude and fatigue lifetime at the various ambient temperatures for the drawn UHMWPE films with draw ratio of 100 .

temperature of $323 \mathrm{~K}$ corresponds to the $\alpha_{1}$-crystalline relaxation temperature at $10 \mathrm{~Hz}$, while that of $348 \mathrm{~K}$ corresponds to the $\alpha_{2}$-crystalline relaxation temperature. The $\alpha_{1}$-mechanism is related to the molecular motion in the intermosaic block region. ${ }^{12,13}$ On the other hand, the $\alpha_{2}$-mechanism is associated with uniform shear deformation of lamellar crystals. ${ }^{12,13}$ In a relaxation temperature region of the intermosaic block (the $\alpha_{1}$-crystalline relaxation), the decomposition of lamellar crystal into the mosaic blocks mainly contributes to the deformation process, ${ }^{12,13}$ the intermosaic region becomes the place of stress concentration which give rise to the decrease in fatigue lifetime at this temperature region. Thus, the fatigue lifetime at $328 \mathrm{~K}$ is shorter than other ambient temperatures. A greater fatigue strength at $348 \mathrm{~K}$ compared with that at $323 \mathrm{~K}$ can be ascribed to the onset of intralamellar crystalline relaxation (the $\alpha_{2}$-crystalline relaxation) at this temperature region.

\section{Variations of Dynamic Viscoelasticity during the Fatigue Process}

Figure 6 shows the variations of the dynamic storage modulus, $E^{\prime}$ and the mechanical loss tangent, $\tan \delta$ with time during the fatigue process at $298 \mathrm{~K}$ for the drawn UHMWPE 


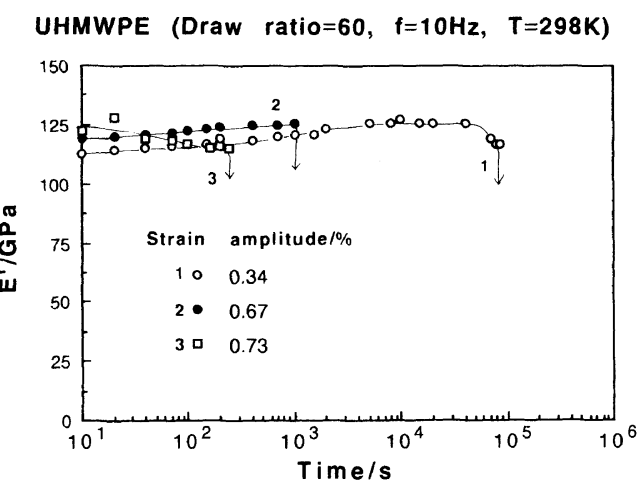

(a)

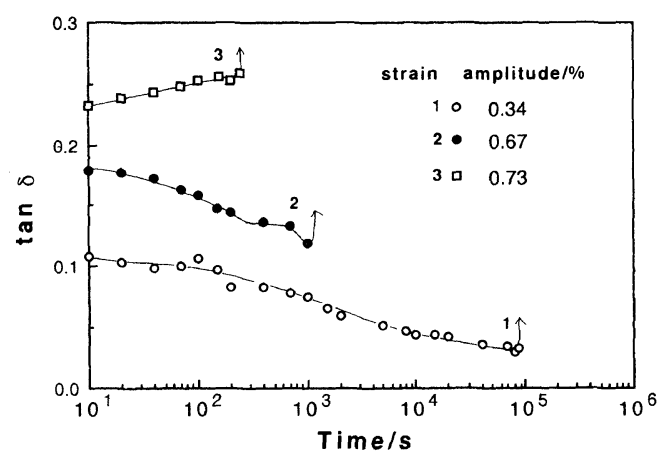

(b)

Figure 6. Variations of $E^{\prime}$ (a) and $\tan \delta$ (b) with time during the fatigue process at $298 \mathrm{~K}$ for the drawn UHMWPE film with draw ratio of 60 .

films with the draw ratio of 60 . In the case of the small imposed strain amplitude of $0.34 \%$, $E^{\prime}$ gradually increases and $\tan \delta$ gradually decreases at an initial stage of fatigue process. Also, the slight maximum of $E^{\prime}$ and the minimum of $\tan \delta$ are observed in the vicinity of fatigue failure. The similar behavior was also observed for the case of brittle failure of unoriented plasticized $\mathrm{PVC}^{7}$ and unoriented high-density polyethylene (HDPE) ${ }^{8,9}$ In the case of these unoriented materials, the characteristic behavior of $E^{\prime}$ and $\tan \delta$ arose from the proceeding of orientation or extension of polymer chains to the direction of cyclic straining at the end of fatigue process. Though a similar behavior was observed for drawn UHMWPE films, the variation of degree of orientation of the $c$-axis under cyclic fatigue

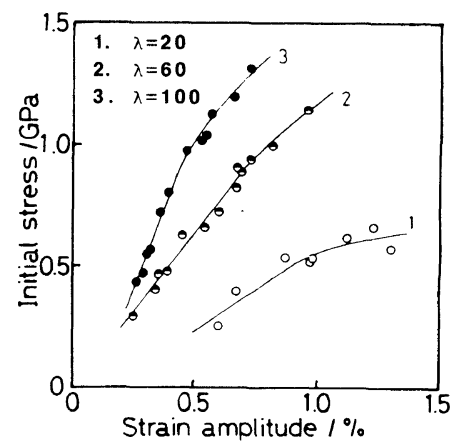

Figure 7. Relationships between initial stress amplitude and dynamic strain amplitude for the drawn UHMWPE films with various draw ratios. The magnitude of stress amplitude was obtained from the initial stress amplitude during fatigue test.

could not be detected by WAXD measurement under the conditions employed in this study since the degree of orientation of $c$-axis was greater than 0.99 at the start of the fatigue testing. In the case of high strain amplitude of $0.73 \%, E^{\prime}$ gradually decreases and $\tan \delta$ gradually increases at the initial process of fatigue test. Under these conditions, $E^{\prime}$ decreased and $\tan \delta$ increased abruptly at the point of failure. In the case of unoriented HDPE specimen with a small ratio of surface area to volume $\left(\mathrm{S} / \mathrm{V}=7.52 \mathrm{~cm}^{-1}\right)$, the variations of $E^{\prime}$ and $\tan \delta$ in the initial stage of fatigue process corresponded to the slight increase in specimen temperature towards attainment of steady state. ${ }^{7}$ This is related to the balance between viscoelastic heat generation under cyclic straining and the heat transfer rate to its surroundings. As the large surface area to volume ratio $\left(S / V=2000 \mathrm{~cm}^{-1}\right)$ of the drawn UHMWPE film suppressed the rising of the specimen temperature during the fatigue process, these variation of dynamic viscoelasticity can be ascribed to the structural change such as scission of molecular chains or slippage of crystallites.

Figure 7 shows the relationship between initial stress amplitude and dynamic strain amplitude for UHMWPEs with various draw ratios. The magnitude of stress amplitude have been 
obtained from the stress amplitude at the initial stage of fatigue process. At the low strain amplitude, the initial stress amplitude linearly increased with the dynamic strain amplitude. However, at the large imposed strain amplitude, the relationship between stress and strain amplitudes deviated from the linear relationship. The stress amplitude observed is smaller than that expected from the linear relationship. Also, the strain amplitude at which the stress deviated from linear relationship decreased with an increase in draw ratio. This nonlinear dependence might be related to the structural change such as the scission of chains or slippage of crystallites under cyclic deformation.

Figure 8 shows the variation of $E^{\prime}$ and $\tan \delta$ with the time during the fatigue process at $298 \mathrm{~K}$ and the imposed strain amplitude of

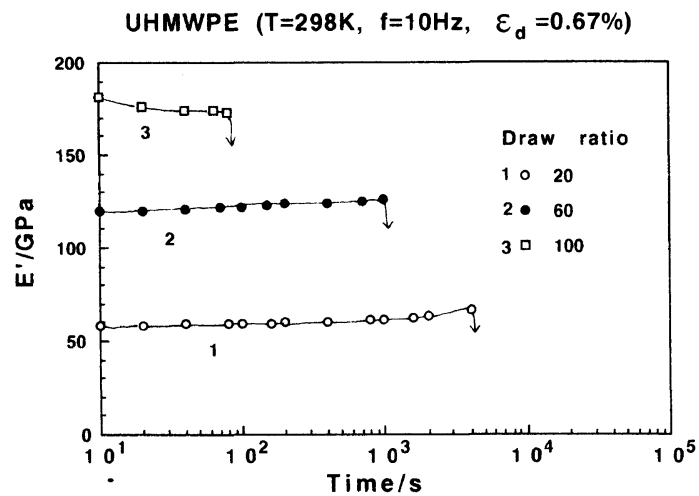

(a)

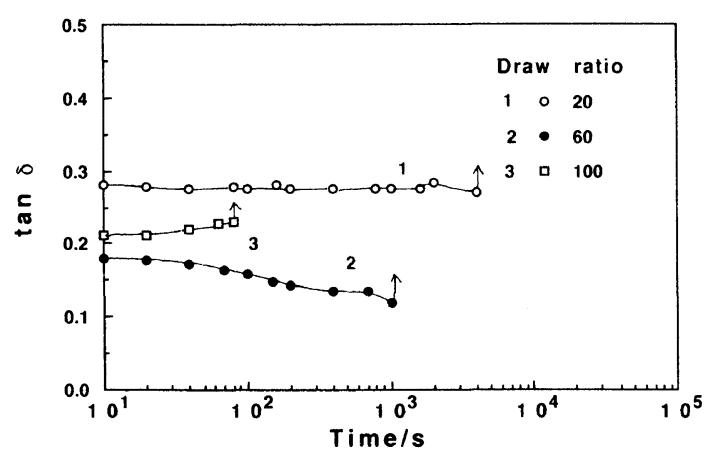

(b)

Figure 8. Variations of $E^{\prime}$ (a) and $\tan \delta$ (b) with time during fatigue process at $298 \mathrm{~K}$ for the drawn UHMWPE films with various draw ratios.
$0.67 \%$ for the UHMWPE films with various draw ratio. The magnitude of $E^{\prime}$ increased with draw ratio. The sample with the draw ratio of 20 showed the slight maximum of $E^{\prime}$ and the minimum of $\tan \delta$ on approaching the point of fatigue failure. This behavior was not observed for the specimens with the high draw ratio of 100. The absence of the maximum of $E^{\prime}$ and the minimum of $\tan \delta$ is due to the almost perfect orientation or a remarkable increase in number of extended chain crystals induced during drawing process.

Figure 9 shows the variations of $E^{\prime}$ and $\tan \delta$ with time during the fatigue process for a drawn UHMWPE film with the draw ratio of 100 as a function of ambient temperature under a strain amplitude of $0.32 \%$. At this strain amplitude level, such a deviation from the

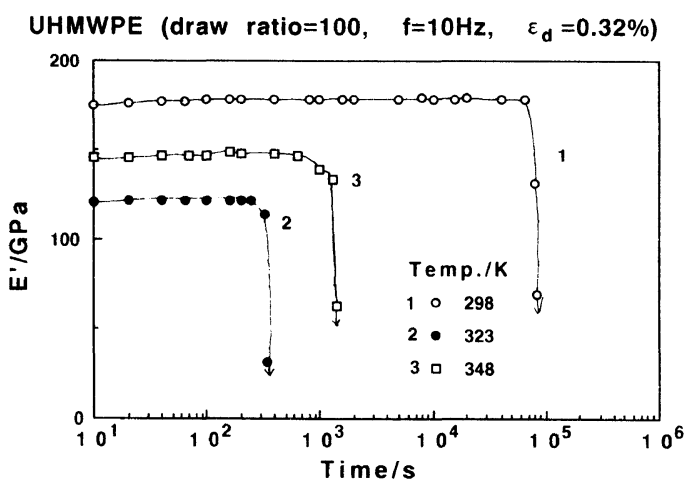

(a)

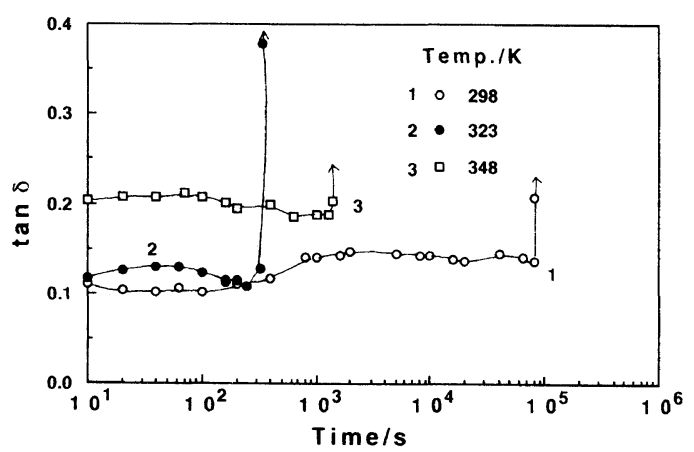

(b)

Figure 9. Variations of $E^{\prime}$ (a) and $\tan \delta$ (b) with time during fatigue process at various ambient temperatures for the drawn UHMWPE films with draw ratio of 100 . 
linear relationship between strain and stress amplitudes was not observed. The fatigue lifetime at $348 \mathrm{~K}$ is longer than that at $323 \mathrm{~K}$ under the same imposed strain amplitude. Also, the magnitude of $E^{\prime}$ and fatigue lifetime at $348 \mathrm{~K}$ were greater than those at $323 \mathrm{~K}$. These behavior can be explained in terms of the mechanical crystalline relaxation process. ${ }^{12,13}$ The $\alpha_{1}$-process is dominant at $323 \mathrm{~K}$, whereas $\alpha_{2}$-process is dominant at $348 \mathrm{~K}$. The $\alpha_{1}$ process is very sensitive to static and dynamic deformation. ${ }^{12}$ Around $323 \mathrm{~K}$, the deformation of intermosaic block region reduced the magnitude of $E^{\prime}$ for highly oriented UHMWPE and then, the fatigue fracture occurred in the relatively short time. On the other hand, as the preferential orientation of the crystallite easily occurred under the uniform shear deformation of lamellar crystals at $348 \mathrm{~K}$. The fatigue lifetime was larger at $348 \mathrm{~K}$ than $323 \mathrm{~K}$ because the deformation mechanism at this temperature was not destructive one. Therefore, it can be concluded that the deformation such as the deformation of intermosaic block region is most influential to fatigue strength for highly oriented polymeric materials.

\section{CONCLUSION}

The fatigue behavior of the drawn ultra-high molecular weight polyethylene (UHMWPE) films prepared by drawing the dry gel film to various draw ratios was investigated. The fatigue lifetime at a certain strain amplitude decreased with an increase in draw ratio. In the case of a film with the draw ratio of 20 , the typical viscoelastic behavior was observed under the small imposed strain amplitude, which suggested proceeding of orientation of molecular chains under cyclic fatigue. The drawn film with high draw ratio of 100 did not show variation of dynamic viscoelasticity until the onset of fatigue fracture. The fatigue strength at $323 \mathrm{~K}$ is lower than those at 298 and $348 \mathrm{~K}$. This suggests the large contribution of deformation mechanisms of crystallites at this temperature region to fatigue mechanism of highly oriented PE.

\section{REFERENCES}

1. A. Cifferi and I. M. Ward, Ed., "Ultra-High Modulus Polymers," Applied Science, London, 1979.

2. A. Zwijnenburg and A. J. Pennings, Colloid Polym. Sci., 254, 868 (1976).

3. P. J. Braham and A. Keller, J. Mater. Sci., 15, 2229 (1980).

4. P. Smith, P. J. Lemstra, B. Kalb, and A. J. Pennings, Polym. Bull., 1, 733 (1979).

5. P. Smith and P. J. Lemstra, J. Mater. Sci., 15, 505 (1980).

6. P. Smith and P. J. Lemstra, Colloid Polym. Sci., 258, 891 (1980).

7. A. Takahara, K. Yamada, T. Kajiyama, and M. Takayanagi, J. Appl. Polym. Sci., 25, 597 (1980).

8. A. Takahara, K. Yamada, T. Kajiyama, and M. Takayanagi, J. Appl. Polym. Sci., 26, 1085 (1981).

9. N. Kaiya, M. Kugishima, A. Takahara, and T. Kajiyama, Sen-i Gakkaishi, 42, T-129 (1986).

10. N. Kaiya, A.. Takahara, and T. Kajiyama, Polym. J., 21, 523 (1989).

11. A. J. Pennings and A. Zwijnenburg, J. Polym. Sci., Polym. Phys. Ed., 17, 1011 (1979).

12. M. Takayanagi and T. Kajiyama, J. Macromol. Sci.-Phys., B8, 1 (1973).

13. T. Kajiyama, T. Okada, and M. Takayanagi, $J$. Macromol. Sci-Phys., B9, 35 (1974). 